\title{
EL MEDIO FÍSICO DE LAS ISLAS BALEARES: SOPORTE DE LAS DIRECTRICES DE ORDENACIÓN TERRITORIAL ${ }^{1}$
}

\author{
José Manchado ${ }^{2}$ \\ Antoni Marcús ${ }^{2}$ \\ Onofre Rullán ${ }^{2}$
}

\section{RESUMEN}

El medio físico es el elemento clave para la ordenación territorial que pretenden las Directrices de Ordenación Territorial de las islas Baleares. El presente estudio constituye el análisis que, para tal fin, se llevó a cabo. Todo ello a partir de información existente que, mediante técnicas SIG, se generalizó y combinó para delimitar unidades físicas homogéneas y proponer figuras de ordenación y gestión. Para la localización y delimitación de las unidades homogéneas se utilizan diferentes mapas: alturas, pendientes, ocupación del suelo, distancia a la costal, vegetación natural, interés faunístico y capacidad agrológica, con los cuales se elaboran los mapas de interés ecológico y paisajístico. Combinando los mapas anteriores se obtiene el mapa de vocación del territorio y, finalmente, se delimitan las Unidades Territoriales en las que predomina una determinada combinación de zonas de similar vocación. La propuesta de ordenación para cada unidad homogénea estableció usos propiciados, permitidos y prohibidos.

Palabras clave: Directrices de Ordenación Territorial, Islas Baleares, SIG, medio físico.

\begin{abstract}
One of the main purposes of The Balearic Regional Government is the redaction of the Regional Planing Directives. They basically describe the land model that is intended
\end{abstract}

1 El presente artículo se ha elaborado a partir del trabajo encargado por la Dirección General d'Ordenació del Territori i Medi Ambient del Govern Balear y forma parte del avance de las Directrices de Ordenación del Territorio de las Islas Baleares. Otras monografías sectoriales completan los trabajos del documento global que ha coordinado Taller de Ideas.

2 El informe original fue elaborado por el Gabinet d'Anàlisi Ambiental i Territorial (GaaT), Av. Gabriel Alomar, 11. 07006-Palma-Mallorca. E-mail: empresa@ gaat.es. Entonces el equipo técnico estuvo compuesto por: Onofre Rullán Salamanca (Director-Geógrafo), Antoni Marcús (Geógrafo), José Manchado (Geógrafo), Martín Llobera (Biólogo), Macià Blázquez (Geógrafo), Joan Llop (Biólogo), Biel Bibiloni (Biólogo). Los autores del presente artículo son asimismo profesores de Geografía del Departamento de Ciencias de la Tierra de la UIB, carretera de Valldemossa km. 7.5, 07071-Palma-Mallorca. 
to achieve for the Balearic territory in the future. Physical environment has been one of the most important features taken into account in order to elaborate the Directives. The present study briefly describes, how physical environment analysis was done, and how important became in the purpose of defining the territorial model for the Balearic Islands. The project consisted basically in the capture of all the information related to physical environment and by using GIS techniques the delimitation of areas with common characteristics which were able to be treated as homogeneous physical units. The location and delimitation's of those homogeneous units was achieved by using several basic thematic maps such as: elevation, slope, land use natural vegetation, faunistic interest, water reservoir fragility, land agrological capacity and potential contamination focuses. The final proposal consisted in the description of promoted, forbidden and permitted uses for emery deferent homogenous unit.

Key words: Regional Planing Directives, Balearic Islands, GIS, physical environment.

\section{Introducción}

Con las Leyes Orgánicas 2, 3 y 4/1983 de 25 de febrero se cierra el mapa autonómico español surgido a partir de la Constitución de 1977. Con ellas las comunidades autónomas de las islas Baleares, Madrid y Castilla y León se dotaron de sus respectivos estatutos de autonomía.

Todos los estatutos de autonomía atribuyen las competencias de urbanismo y ordenación del territorio a los gobiernos y parlamentos autónomos ${ }^{3}$, entre ellos el de las islas Baleares ${ }^{4}$. A partir de entonces se generaron toda una serie de Leyes de Ordenación Territorial (LOT) que, con distintos nombres, implementarán tal competencia (Rullán Salamanca 1995c, p. 181).

Como ya expusimos en otra ocasión:

Desde el punto de vista instrumental estas leyes autonómicas de ordenación del territorio presentan dos novedades principales: la sustitución de los Planes Directores Sectoriales de Coordinación (PDTC) de la Ley del Suelo como posible figura de ordenación de la totalidad de la Comunidad Autónoma, por las Directrices de Ordenación Territorial (Plan Territorial General de Cataluña, Plan de Ordenación del Territorio del País Valenciano); y el establecimiento de figuras de ordenación de ámbito geográfico supramunicipal e infrautonómico

(Rullán Salamanca 1995c, p. 182).

Las directrices, frente a las figuras de ordenación territorial posibles hasta entonces, suponen un novedoso cambio de enfoque:

Con las DOTs se establecerán criterios de ordenación frente a las determinaciones propias de los PDTCs. Un desencorsetamiento de la Ordenación del

3 El artículo 148 de la Constitución establece, entre otras, que las Comunidades Autónomas podrán asumir competencias en Ordenación del Territorio, Urbanismo y Vivienda, (Art. 148.1.3 ${ }^{\mathrm{a}}$ ).

4 Este atribuye competencia exclusiva a nuestra comunidad en materia de ordenación del territorio, litoral incluido, urbanismo y vivienda (Art. 10.3). 
Territorio que por razones de escala parece más que necesaria. La tendencia flexibilizadora y desreguladora, no finalista de las políticas territoriales, que ahora se autodefinen como estratégicas, han hecho inevitable tal cambio en las figuras de ordenación que abarcan ámbitos territoriales tan extensos como las CCAA. Las Directrices serán desarrollables normativamente con figuras de rango inferior, mientas que los PDTCs aportaban determinaciones directamente vinculantes. En algunos casos las Directrices se reservan algunos aspectos determinantes, normalmente infraestructuras y protección de Espacios Naturales. Estos son los elementos que confieren estructura al modelo territorial propuesto por aquellas.

(Rullán Salamanca 1995c, p. 182).

Pioneras en este campo, las Directrices Regionales de Ordenación del Territorio del Principado de Asturias de $1991^{5}$, inaugurarán esta nueva generación de planes territoriales que, reemplazando los nonatos PDTCs, se basarán en el criterio y la estrategia más que en la determinación y la táctica. Cuatro años más tarde, en 1995, Cataluña aprobó su Plan Territorial General ${ }^{6}$ (Generalitat de Catalunya 1995). A principios de 1997 verán la luz las Directrices de Ordenación Territorial del País Vasco 7 .

El resto de comunidades autónomas se encuentran en diferentes fases de elaboración de sus correspondientes planes territoriales autonómicos. Algunas comunidades optan por Normas Subsidiarias Provinciales para acometer problemas urbanísticos obviando los territoriales; otras, como Canarias, van aprobando uno a uno los correspondientes planes insulares $^{8}$. Existen comunidades que han hecho varios intentos de aprobación ${ }^{9}$ mientras otras las están elaborando ahora mismo ${ }^{10}$. El resto tienen el desarrollo de sus respectivos planes en fase todavía más precaria, algunas ni tan siquiera cuentan todavía con LOT autonómica ${ }^{11}$.

En las islas Baleares es la Ley de Ordenación Territorial de 1987 la que establece las DOTs como instrumento de ordenación integral del archipiélago balear. Dichas directrices se encuentran actualmente en fase de avance, habiéndose elaborado toda una serie de informes temáticos y propuestas de ordenación que deberán fructificar en su aprobación definitiva.

El trabajo que aquí presentamos, sobre el Medio Físico de las Islas Baleares, forma parte del conjunto de ocho informes temáticos que integran el Análisis Territorial para el Avance de las Directrices de Ordenación Territorial de la comunidad autónoma de las Islas Baleares. En el que nos ocupa se da cobertura a los aspectos específicos del medio natural,

5 Decreto 11/1991 de 24 de enero de aprobación de las Directrices Regionales de Ordenación del Territorio (LPAS de Aranzadi 1991-26, pp. 54-112). La ley 1/87 de Coordinación y Ordenación Territorial, en la que se basan estas directrices, prevé el desarrollo de Directrices Subregionales como concretización de aquellas. En este sentido ya han sido aprobadas las que afectan la franja costera asturiana mediante el decreto 107/1993 de 16 de diciembre de aprobación de la Directrices Subregionales para la Franja Costera (LPAS de Aranzadi 1994-27, pp. 55-95).

6 Llei 1/1995, de 16 de març, per la qual s'aprova el Pla Territorial General de Catalunya.

7 Puede consultarse, al efecto, el libro editado en ocasión de su aprobación inicial en 1994 (Gobierno Vasco 1994).

8 Hasta el momento tenemos noticia de la aprobación de los de Lanzarote, Gran Canaria y Hiero.

9 Madrid, Cantabria y la Rioja han tramitado diferentes documentos sin llegar a su aprobación definitiva.

10 Como la Comunidad Valenciana, las Islas Baleares y Castilla y León que elabora, esta última, paralelamente su LOT y sus DOTs.

11 Para una visión general, aunque no exhaustiva ni actualizada, del estado de la cuestión en diferentes CCAA, puede consultarse el número 95-96 de Ciudad y Territorio. Estudios Territoriales de 1993. 
unos aspectos que han sido considerados de especial relevancia a la hora de formular el análisis a partir del cual ha sido establecida la hipótesis del modelo territorial de las Islas Baleares (Taller de Ideas 1996).

En esta monografía los aspectos del medio físico se han contemplado, lejos de consideraciones sectoriales, como integrados en la totalidad del modelo territorial vigente y, consecuentemente, del propuesto. Medio natural como soporte de actividades humanas actuales y futuras, medio natural analizado con el objetivo de determinar la capacidad de carga de dichas actividades. En base a estos supuestos se ha redactando el informe temático en cuestión ${ }^{12}$.

\section{La información territorial}

Los planes, sean locales o territoriales, normalmente gastan cantidades ingentes de energía en unas fases de información y diagnóstico que, lejos de cumplir los objetivos marcados, en el mejor de los casos pretenden cubrir los déficits de investigación básica que los autores de los mismos piensan que existen.

De esta manera se da una curiosa y no contabilizada subvención a la investigación básica por parte de los fondos que los presupuestos públicos inicialmente pensaron destinar al reordenamiento y a la acción territorial. Como si la Geografía Aplicada subvencionara el trabajo geográfico de carácter básico.

Como sea que los departamentos de la administración territorial no están concebidos, pensados, ni preparados para la tutela científica de la nueva investigación básica, toda esta nueva producción suele aprobar en ocasiones sin tan siguiera pasar un mínimo examen. Total, para la administración, lo único interesante serán los textos articulados que, de volumen ostensiblemente inferior, mandarán a los correspondientes boletines oficiales.

A nuestro entender las fases de información y diagnóstico no deben incorporar investigación básica. Esta debería elaborarse y subvencionarse por vía académica. Los planes, como hijos que son de los tiempos en que se elaboran, se construirían así a partir de las investigaciones básicas disponibles en cada momento y podrían invertir la totalidad de sus energías en lo que les es encomendado: la Ordenación del Territorio.

De esta manera un doble objetivo se conseguiría. Por un lado la investigación académica tendría una función aplicada indirecta pero decisiva que proporcionaría satisfacción a los deprimidos por la cuestionada utilidad de los conocimientos académicos. Por otro se conseguiría una conexión muy provechosa entre academia y sociedad, a más investigación básica más posibilidades de políticas territoriales coherentes.

Este modelo sólo plantea un problema: quizás algunas de las investigaciones básicas que se van realizando resultarían ser, con este sistema, efectivamente inútiles. Del mismo modo algunos planificadores urbanos y territoriales, al no poder dedicarse a las memorias de información, no conseguirían aportar nada concreto, propositivo y aplicado, con lo que también se revelarían, como los informes que elaboran, totalmente inservibles.

En la línea de este tipo de planteamientos, el trabajo presentado pretende una recopilación de la información existente sobre el medio natural de nuestra Comunidad tanto en el ámbito de la Administración Pública (Govern Balear, Consells Insulars, Ayuntamientos), como universitaria además de otra información publicada. Por otra parte se recopiló asimismo la legislación y planes existentes en materia de conservación del medio natural en las Islas Baleares (leyes marco de actuación, sistemas de protección actualmente vigentes, planes territoriales y sectoriales aprobados o en vías de aprobación, etc.).

12 Los autores trabajan asimismo — enero de 1997- en la elaboración del documento definitivo. 
Uno de los mayores problemas con que se enfrenta el planificador es la sintetización de la información. La que recopilamos, en muchos casos era excesivamente detallada para los objetivos que nos proponíamos. Como casi siempre ocurre, contrariamente a lo que se predica, no falta información sino que sobra, lo que falta es tratarla y saber utilizarla para los objetivos planteados que, eso si, deben existir.

La necesaria sintetización se ha llevado a cabo fundamentalmente, como geógrafos que somos, de forma cartográfica, cambiando escalas y generalizando la información. La labor de análisis ha sido también uno de los aspectos importantes del trabajo. Partiendo de la información existente, debidamente informatizada en el contexto de un Sistema de Información Geográfica (SIG) ${ }^{13}$, ha sido posible aplicar técnicas de análisis geográfico que han permitido la ordenación de la información existente y su combinación obteniéndose mapas nuevos, tales como riesgos naturales (riesgo de contaminación de aguas y de deterioro de ecosistemas), interés paisajístico y finalmente las delimitaciones de las unidades territoriales físicas susceptibles de ordenación.

La utilización de Sistemas de Información Geográfica cuenta, en Mallorca, con una historia de apenas 10 años. Efectivamente en 1988 se presentaba, en la entonces llamada Consellería de Obras Públicas y Ordenación del Territorio de les Islas Baleares, la fase de información y diagnóstico de lo que debiera haber sido el Plan Territorial Parcial ${ }^{14}$ de la serra de Tramuntana mallorquina (Equip Tramuntana 1988). Sintomáticamente en dicho trabajo no aparecen las hoy tan populares siglas $\mathrm{SIG}^{15}$. No obstante para la elaboración del mismo se programó un auténtico SIG ráster (Ruiz Pérez et al. 1991), inspirado en el entonces ya conocido en España programa $\mathrm{MAP}^{16}$. A partir de este trabajo la aplicación de los SIGs a temas de planificación territorial experimentó un crecimiento exponencial ${ }^{17}$.

El proyecto aquí presentado, entroncando con las experiencias anteriores, constituye el primer SIG Vectorial que abarca la totalidad de del archipiélago balear, al tiempo que supone un paso de gigante a la hora de valorar el trabajo de los geógrafos entre la jungla competencial intergremial. Es, en suma, una aportación al binomio, pensamos que inseparable, Geografía-Planificación.

\section{El Informe Temático número 2 (IT2) de las DOT}

El contenido del IT2 se estructura de la siguiente forma:

Un primer apartado en el que se realiza el análisis de la situación actual de los diferentes aspectos temáticos del medio físico (vegetación, fauna, ocupación del suelo, vulnerabilidad de acuíferos, focos de contaminación ambiental, etc.), los cuales, a su vez,

13 El sistema utilizado ha sido ArcInfo.

14 Figura de ordenación supramunicipal de tipo integral prevista por la LOT balear.

15 De hecho el término SIG empieza a popularizarse en los departamentos de geografía españoles en general y el de la UIB en particular a partir de la celebración del I Curso sobre enseñanza e investigación asistidas por ordenador: Los sistemas de información en Geografía. que dirigió el Dr. Juan A. Cebrián de Miguel y que fue organizado por el Departamento de Geografía de la Universidad de Extremadura, y al que asistimos algunos de los actuales profesores del DCT-UIB. Dicho curso tuvo lugar en Cáceres del 30 de septiembre al 5 de octubre de 1988.

16 En octubre de 1987 el Departament de Ciències de la Terra de la UIB organizó el seminario: Técnicas de Ordenación del Territorio: el MAP, que impartió el profesor Pau Alegre i Nadal y que serviría decisivamente para el diseño del programa mallorquín pionero en el campo del SIG.

17 En departamento de Ciencias de la Tierra la UIB se organizó, a partir de 1990, el entonces llamado Laboratori d'Anàlisi Ambiental i Territorial (LaaT) que, en 1993, sería sustituido con la creación del Laboratori de Sistemes d'Informació Geogràfica (LSIG) específicamente dedicado a estos temas. En el campo de las empresas privadas es de destacar la constitución, en 1994, del Gabinet d'Anàlisi Ambiental i Territorial (GaaT). 
servirán de base para la obtención de nueva información temática, a partir de su análisis geográfico.

Una segunda parte en el que se sintetizan los sistemas de protección de la naturaleza vigentes ahora mismo en las Islas Baleares.

Un tercer apartado en el que se realiza un diagnóstico de los principales problemas que afectan al medio natural del archipiélago (sus principales agresiones, las carencias de información existentes en cada uno de sus aspectos, etc.), así como las principales oportunidades o posibilidades que presenta.

Un cuarto apartado en el que se traza una línea direccional hacia la cual debería encaminarse la política territorial y medioambiental de las Islas Baleares.

Un quinto apartado en el que se describen las unidades territoriales en función de su interés ecológico, paisajístico y agrológico. Estas servirán de base para la delimitación de unidades físicas sobre las que se trazarán propuestas de ordenación territorial.

Y un sexto apartado final en el que se proponen las figuras de gestión más adecuadas para corregir los problemas detectados.

El principal interés para el análisis geográfico aplicado reside en los apartados 1 —en concreto la elaboración de algunos mapas de riesgos-, 5 -delimitación de unidades territoriales homogéneas y 6 propuestas-. A ellos vamos a dedicar nuestra atención remitiéndonos al trabajo original (Gabinet d'Anàlisi Ambiental i Territorial 1995) para el resto de cuestiones tratadas.

\section{Los mapas de riesgos}

El estudio de los riesgos ambientales se aborda de acuerdo al fluxograma siguiente:

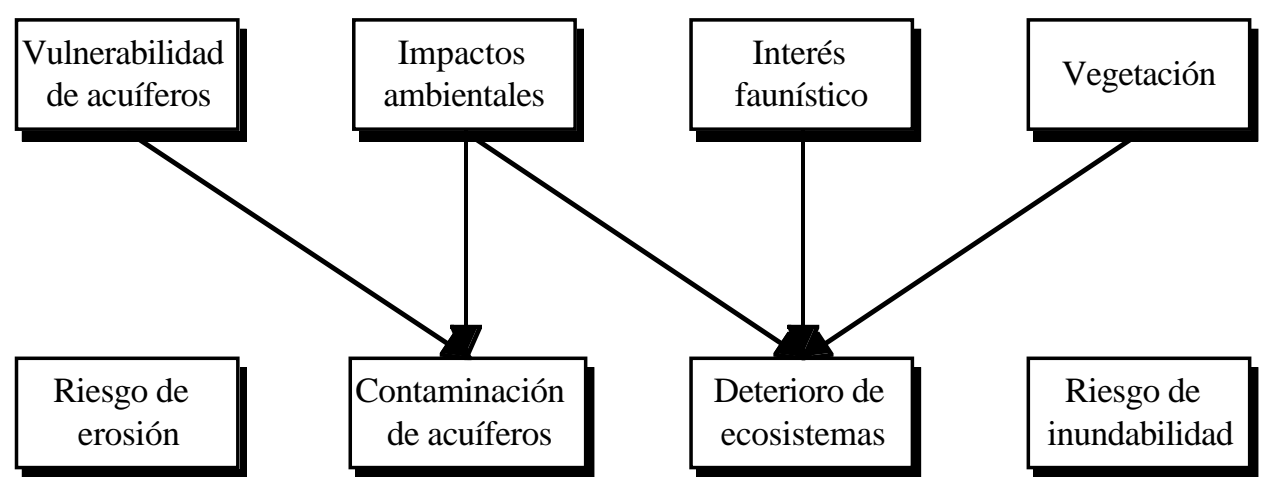

Como puede observarse de los cuatro mapas que constituyen la cartografía de riesgos dos de ellos, erosión e inundabilidad, han sido manejados — digitalización, generalización y homogeneización de leyendas- a partir de información y documentación ya conocida ${ }^{18}$. Los otros dos - contaminación de aguas y riesgo de contaminación de ecosistemaspueden revestir mayor interés metodológico por tratarse de mapas que, elaborados a partir de información cartográfica existente, muestran una zonificación del riesgo que no se detecta analizando separadamente cada uno de los elementos que lo integran.

18 Para el de erosión se contó con el Mapa de Estados Erosivos de las Islas Baleares, publicado por el ICONA en 1994 y para el de inundabilidad con el estudio de Miquel Grimalt i Gelabert de 1992: Geografía del risc a Mallorca. Les Inundacions. 
El mapa de contaminación actual y potencial de los acuíferos de les Islas Baleares.

Sin duda alguna, la causa más importante en la actualidad de degradación del agua, y consiguiente disminución de los recursos hídricos de las islas, es el proceso de intrusión de agua de mar aportando niveles de cloruros a los acuíferos.

Asimismo son de destacar como focos importantes de contaminación de las aguas subterráneas, las actividades agrícolas y ganaderas intensivas, principalmente los cultivos de regadío, cuyas técnicas de fertilización de las tierras producen serios daños por infiltración de nitratos a los acuíferos subyacentes.

En el correspondiente mapa de focos de contaminación de aguas, quedaron reflejadas las zonas actualmente afectadas por estos dos focos de contaminación, realizado a partir de dataciones reales del estado de los acuíferos. La superposición de ambos niveles de contaminación, cloruros y nitratos, nos proporciona una visión global del problema de las intrusiones.

No obstante, el mapa de riesgo de contaminación de aguas subterráneas, pretende ir más allá. Partiendo de la información sobre puntos potenciales de contaminación, y de la información que nos dan los mapas de vulnerabilidad de acuíferos, por superposición de capas se han detectado aquellos puntos que se sitúan sobre zonas con posibilidad máxima de alteración de la calidad de las aguas subterráneas. Para ello se han seleccionado aquellos puntos donde se realizan vertidos de residuos líquidos (principalmente en cauces de torrentes, en pozos absorbentes, e incluso aquellos sistemas de eliminación de efluentes para regadío procedentes de poblaciones muy importantes como Palma) y los puntos donde se realizan vertidos de residuos sólidos urbanos (vertederos de basuras).

Uno de los principales problemas a la hora de establecer zonas de riesgo de contaminación es la dificultad para establecer los límites exactos del área de influencia del impacto. Recordemos que en el caso de los vertidos de residuos líquidos en cauces, el área de influencia de ese vertido se amplia aguas abajo. Aunque el vertido se realiza en una zona impermeable, el riesgo de contaminación no desaparece, ya que al discurrir superficialmente se desconoce el área final de infiltración, que puede encontrarse en algunas zonas de máxima posibilidad de alteración.

Para dar alguna solución a este problema, se ha aplicado un radio de influencia de 500 metros a cada uno de los focos potenciales de contaminación que, aunque insuficientes en los casos de vertidos líquidos que discurren superficialmente, como mínimo indican si en el interior de ese radio se encuentra alguna zona de máxima vulnerabilidad.

El resultado es un mapa de localización de las zonas de mayor riesgo de contaminación por intrusión de cloruros y/o nitratos más los puntos de vertidos ponderados en función del diferente grado de vulnerabilidad del acuífero sobre el que se localizan (Mapa 1).

\section{El mapa de riesgos de deterioro de ecosistemas.}

Los factores o acciones que ponen en peligro los ecosistemas naturales pueden ser muy variados. Desde la presión que supone la proliferación desmesurada de urbanizaciones en áreas de elevado interés ecológico, hasta la simple introducción de especies faunísticas que, por su elevada competencia, ponen en peligro otras especies propias de las islas, el riesgo de deterioro del medio natural es extremadamente variado. En este apartado se han tenido en consideración aquellos impactos que por su incidencia pueden poner en mayor peligro el equilibrio de los ecosistemas.

Para la elaboración del mapa de riesgo de deterioro de ecosistemas, se han tomado en consideración las siguientes tipologías de impactos: los impactos urbanísticos, las canteras en activo, los vertederos ilegales de residuos sólidos y la misma presión recreativa del ser humano sobre el medio natural.

La delimitación de lo que podríamos denominar ecosistemas, se ha establecido a partir 


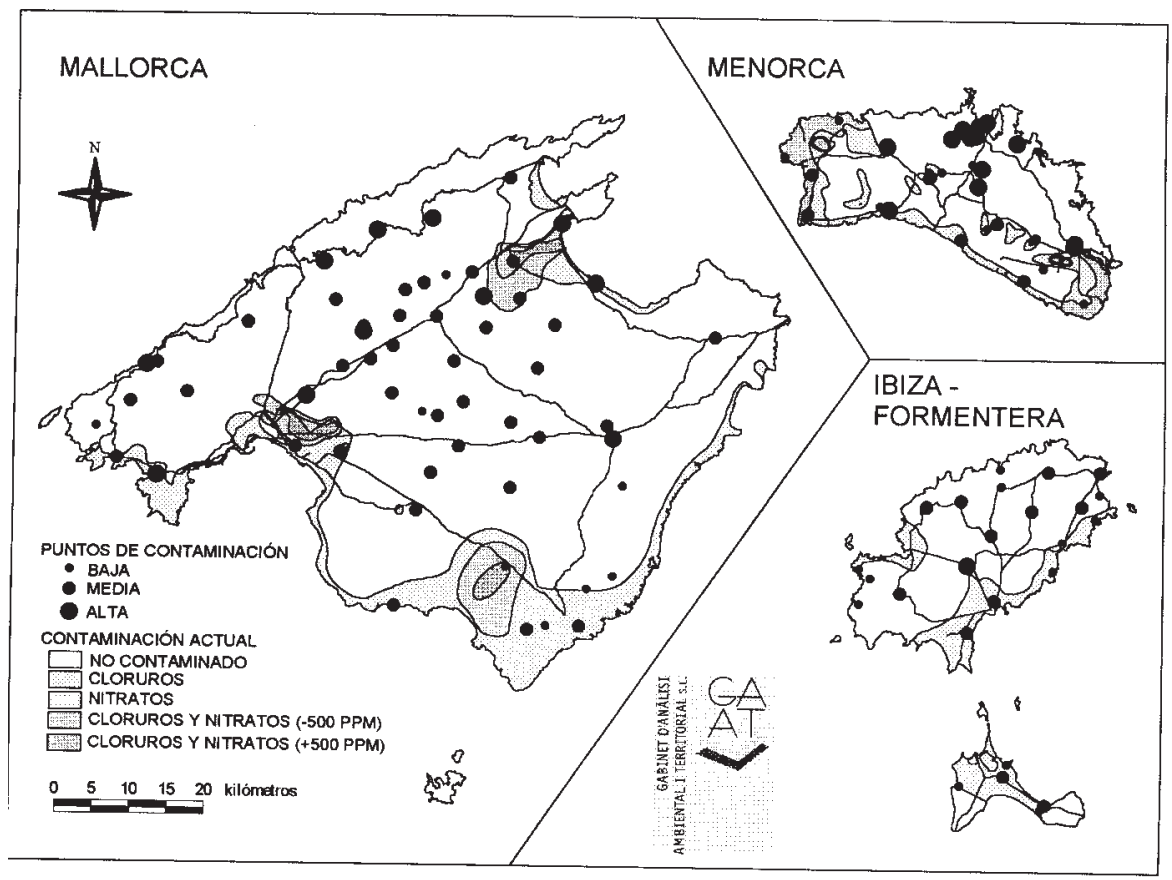

MAPA 1. Contaminación actual y potencial de los acuíferos.

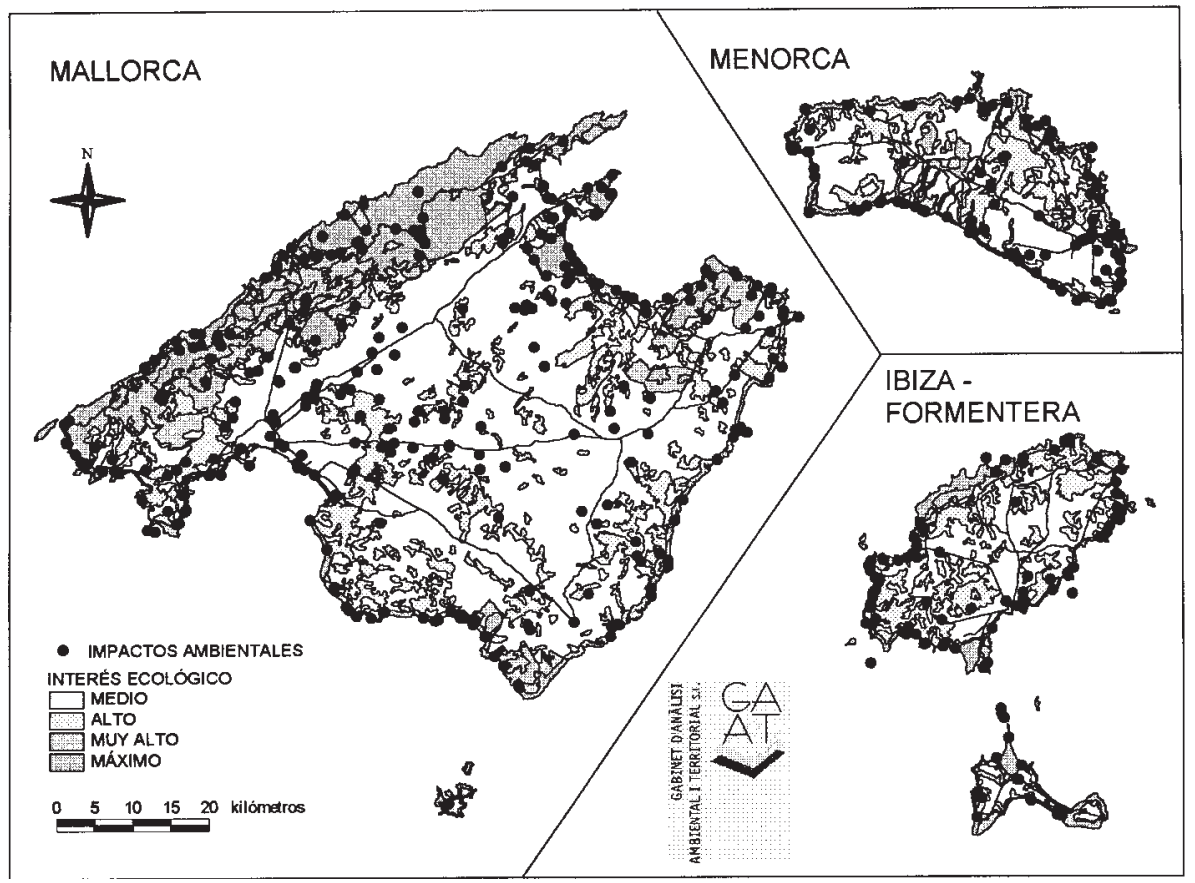

MAPA 2. Riesgo de deterioro de ecosistemas. 
de los diferentes mapas temáticos que hacen referencia específica al medio biótico de las islas y sobre el que más adelante nos extenderemos. Al igual que se hizo con el mapa de riesgos de contaminación de las aguas subterráneas, se estableció una zona de influencia de 500 metros (dadas las características de los impactos considerados) para cada uno de los puntos de impacto potencial. Se eligieron tan solo aquellos impactos que habían sido considerados de intensidad media o alta. Se eliminaron los de intensidad baja por no presentar, en la mayoría de los casos, riesgo alguno de deterioro del medio natural.

Una vez delimitadas las áreas de interés ecológico y establecidos los puntos de deterioro del medio natural, mediante su cruzamiento se han localizado aquellos puntos en los que coincide el impacto sobre una zona de especial interés ecológico. De esta forma se obtiene una radiografía de las zonas más importantes ecológicamente afectadas por impactos sobre el medio natural. El resultado final manifiesta, sin duda alguna, la fuerte presión existente sobre litoral balear, tanto por lo que se refiere a nuevas construcciones, como a la misma presión recreativa que el hombre ejerce sobre el mismo, degradando sus zonas más preciadas (Mapa 2).

\section{La delimitación de unidades territoriales homogéneas del medio físico}

La parte más sustancial del trabajo y de mayor interés geográfico lo constituye, sin duda, el proceso de delimitación de áreas homogéneas del medio físico estudiado mediante la utilización de técnicas SIG.

El objetivo de tal zonificación era doble. Por un lado se pretendía el establecimiento de áreas homogéneas para, sobre ellas, implementar a la vez, políticas territoriales $\mathrm{y}$, a medio plazo, también urbanísticas. Soluciones homogéneas para situaciones, como mínimo, similares. Por otro lado la zonificación, aunque del medio físico, debía incorporar la variable humana. Especialmente desde la Geografía no pueden ser planteados los análisis del medio físico o natural como variable independiente de la actividad humana ${ }^{19}$, hacerlo es grave desde el punto de vista analítico, desde el punto de vista de la Ordenación del Territorio puede tener consecuencias inmediatas no deseables.

Así pues, partiendo de las características definidas y analizadas en los primeros apartados, y mediante técnicas SIG se ha construido un mapa de síntesis final que, estableciendo las unidades homogéneas en cuestión, pretende, para cada una de ellas, realzar su vocación o aptitud para los usos planteados o que, en el futuro, puedan plantearse.

La búsqueda de vocaciones o aptitudes territoriales del medio físico cuenta ya con cierta tradición en los análisis de base para la planificación territorial. En los años 70 empezó a popularizarse el libro que, en Nueva York, había publicado MacHard en 1969 (MacHard 1969). Así y a partir de los trabajos pioneros del biólogo González Bernáldez (González Bernáldez 1973) así como desde el campo de la ingeniería forestal (Gómez Orea et al. 1978), (Gómez Orea 1978), (Ramos 1979), este tipo de trabajos se fueron abriendo camino en un contexto eminentemente multidisciplinar (MOPU-CEOTMA. 1984). Desde la Geografía, en esta época, son de destacar diferentes aportaciones (Alegre 1983), (EGEOGRAN 1983), que, en los últimos años se han visto notablemente incrementados ${ }^{20}$.

19 Aunque no sea de nuestra competencia pensamos que otras ciencias, como la Geología o la Biología, tampoco deberían hacerlo.

20 Existe una notable correlación inicial entre la utilización de técnicas GIS y los estudios de vocaciones del medio físico. En una segunda fase han ido penetrando en el campo de la Geografía otras aplicaciones para la planificación que, utilizando SIGs, tratan temas tales como, por ejemplo, transportes o geomárqueting. 
Así se llevaron a cabo un importante número de estudios que, con similares metodologías, pretendían descubrir el uso más idóneo para unas condiciones geográficas dadas. Estos trabajos pretendían hacer hablar al territorio. Si se nos permite la ironía, es la llegada de la democracia más allá de los individuos, el espacio geográfico era entendido como sujeto activo en el quehacer territorial al que, incluso, se le debía pedir su opinión y, evidentemente, actuar en consecuencia.

La visión en perspectiva de todos estos trabajos y, sobre todo, la comprobación de sus consecuencias tangibles aporta, creemos, un dato que vale la pena retener y destacar. La información básica, los mapas temáticos, necesarios para implementar correctamente este tipo de modelos, contrariamente a lo que en un principio se supuso, son pocos. Como mínimo menos que los que se pensaba. Al final, queramos o no, el mapa temático no contaminado por otras variables, el mapa temático puro, no existe. Máxime si pretendemos, como pretendíamos incluir directa o indirectamente la influencia humana en el medio físico.

A partir de ahí la excesiva carga de información básica deviene redundante, reiterativa y artificializadora de las propuestas que puedan surgir de dichos modelos. Una vez más hay que insistir, no falta información, falta un correcto manejo de la existente que es tanto como decir que falta un correcto análisis geográfico. Con estas premisas se ha llevado a cabo el trabajo de búsqueda de unidades territoriales homogéneas

El cruzamiento de capas, la más elemental de las utilidades SIG, se ha usado para delimitar las unidades territoriales en función de distintos tipos de valoraciones: interés ecológico, interés paisajístico e interés productivo desde el punto de vista agrícola. El halo humano en este tipo de intereses resulta más que notable.

El fluxograma siguiente no sitúa esta parte del trabajo:

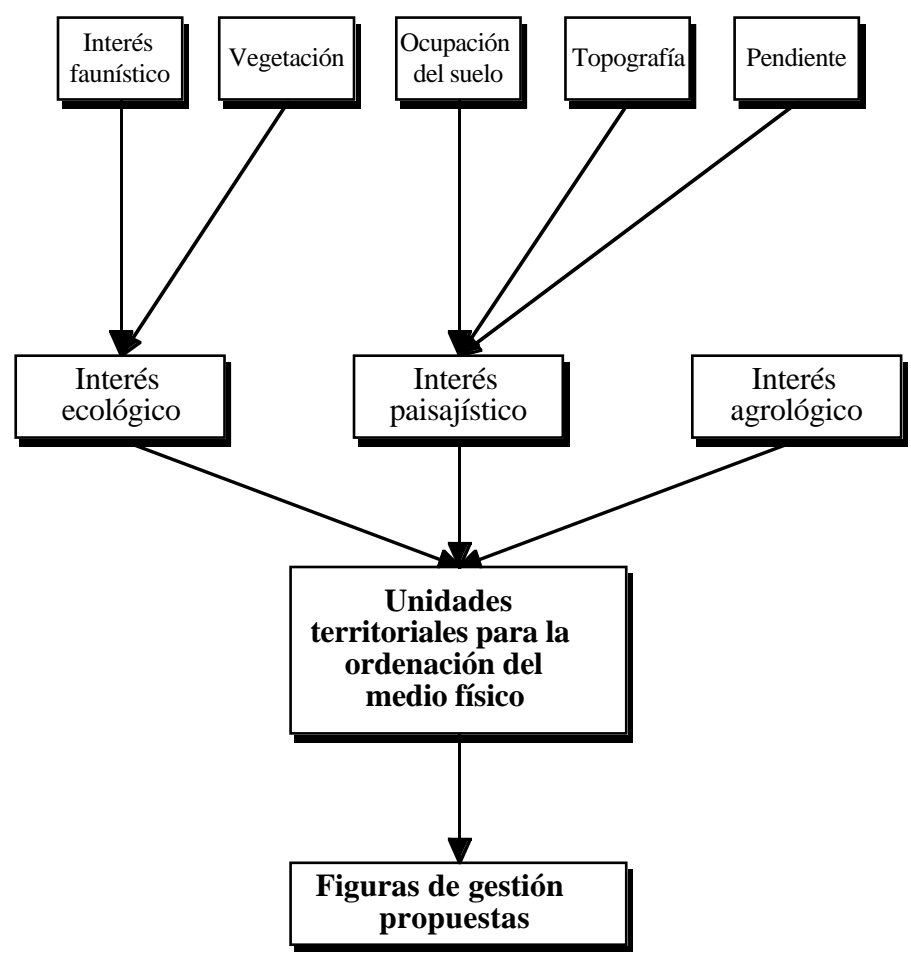


Este mapa de vocaciones — discontinuas y homogéneas- nos permitieron, en una fase final, la definición de las grandes unidades físicas para la ordenación del territorio - continuas y heterogéneas-.

La primera fase ha consistido, pues, en la producción de una cartografía en la que se establecieran las delimitaciones de las vocaciones en base a los intereses anunciados: paisajístico, ecológico y productivo en el sentido de la capacidad agrícola de los suelos.

\section{El interés paisajístico}

El término paisaje ha sido utilizado con diversos significados. Desde la concepción clásica, que entendía el paisaje como simple trasfondo estético de la actividad humana, hasta la concepción actual donde el paisaje tiende a definirse como recurso. En este trabajo, el paisaje se contempla como un elemento comparable al resto de los recursos: vegetación, fauna, suelos, etc. Puede, por tanto, como los demás recursos, necesitar protección, y puede y debe intervenir en la determinación de la capacidad y la fragilidad del territorio para el desarrollo de las actividades humanas.

En este sentido, la valoración de la calidad paisajística del territorio se ha llevado a cabo a partir de métodos indirectos de valoración, cuantitativos y cualitativos, que evalúan los componentes del territorio y que determinan la calidad del paisaje.

Siguiendo la metodología de Gómez Orea (Gómez Orea 1978), estas han sido las fases para la valoración:

Selección de los componentes a considerar

Medición de los componentes sobre información cartográfica

Establecimiento de los pesos o coeficientes de ponderación con que cada elemento contribuye a la calidad

Combinación de las fases precedentes para obtener un valor de la calidad visual global del área en cuestión

Los componentes básicos que se consideraron para el análisis de la valoración paisajística del territorio balear fueron: la topografía $a^{21}$, la clinometría ${ }^{22}$, la ocupación del suelo ${ }^{23}$ y la proximidad a la $\operatorname{costa}^{24}$. El resultado será, de esta forma, una valoración paisajística en función del valor fisiográfico del territorio, en función de sus características físicas intrínsecas.

Una vez obtenidos los componentes básicos para la valoración se procedió al establecimiento de los pesos o coeficientes de ponderación con el que cada componente y elementos contribuían a la calidad. Para ello se utilizaron técnicas democráticas a partir de valoraciones paneles de expertos se ponderaron, para cada una de las islas, los mapas en el modelo general de valoración paisajística.

21 Para el análisis topográfico se digitalizó el mapa topográfico 1:100.000 de las islas menores (Menorca, Ibiza y Formentera) con una equidistancia de 40 metros, y se utilizó el mapa topográfico en formato digital de la Conselleria d'Obres Públiques, digitalizados sobre una base cartográfica 1:50.000 con equidistancias de $100 \mathrm{~m}$

22 Para el análisis clinométrico se utilizaron los mapas de pendientes del Mapa de Estados Erosivos de las Islas Baleares del ICONA. Estos mapas fueron digitalizados a escala 1:200.000 para el caso de Mallorca y a 1:150.000 para el resto de las islas.

23 A partir de una simplificación del Mapa de Cultivos y Aprovechamientos, escala 1:200.000, del Ministerio de Agricultura pesca y Alimentación

24 Se estableció un umbral de $1 \mathrm{Km}$. para todas las islas, con lo cual quedaron delimitadas las zonas próximas a la costa y las zonas de interior. 
Los pesos y coeficientes finalmente utilizados son los que reflejan la tabla siguiente:

\begin{tabular}{|l|c|c|c|c|c|c|c|c|c|c|}
\cline { 2 - 9 } \multicolumn{1}{c|}{} & Peso & $\mathbf{1}$ & $\mathbf{2}$ & $\mathbf{3}$ & $\mathbf{4}$ & $\mathbf{5}$ & $\mathbf{6}$ & $\mathbf{7}$ & $\mathbf{8}$ & $\mathbf{9}$ \\
\hline Alturas $^{25}$ & 1 & 3 & 6 & 9 & & & & & & \\
Pendientes $^{26}$ & 1 & 3 & 6 & 9 & & & & & & \\
Ocup. del suelo $^{27}$ & 2 & 1 & 3 & 7 & 9 & 6 & 5 & 0 & 9 & 9 \\
Prox. a la costa $^{28}$ & 1 & 0 & 9 & & & & & & & \\
\hline
\end{tabular}

Estos pesos han sido asignados a cada una de las clases de las componentes y posteriormente mediante técnicas SIG - uniones y disoluciones - se han obtenido los mapas de interés paisajístico. El resultado ha sido un mapa con un total de 39 combinaciones paisajísticas resultantes, con valores cuantitativos que oscilaban entre el 6 y el $45^{29}$.

\section{El interés ecológico}

El establecimiento de las áreas territoriales con valor ecológico debe plantearse como punto de partida en cualquier política de ordenación del medio natural. El perfecto conocimiento del patrimonio natural de las Baleares debería propiciar una buena estrategia a seguir en la política de protección, ordenación y gestión de las área de mayor valor ecológico.

Este apartado pretende delimitar, a partir de la información temática básica recopilada, los límites físicos de las áreas con valor ecológico. Un valor ecológico que deberá entenderse como la combinación de los distintos valores naturales del medio físico: el valor de la cobertura vegetal existente y el valor de los ecosistemas animales que habitan en ese territorio. Desde este punto de vista, la información temática que ha servido como soporte para la delimitación de estas áreas ha sido básicamente: la vegetación natural, las comunidades vegetales más relevantes y las zonas con un interés faunístico más importante.

$\mathrm{Al}$ igual que en la elaboración del mapa de interés paisajístico, se han utilizado técnicas de análisis geográfico, en el contexto SIG, para la delimitación de las unidades de interés ecológico. Del mismo modo que para el análisis de la calidad paisajística se establecieron valoraciones para cada uno de los elementos de los componentes del análisis, en este caso se ha procedido de la misma forma.

La diferencia fundamental con el mapa de interés paisajístico, radica exclusivamente en que en este caso la mayoría de componentes que entran en juego (vegetación natural, comunidades vegetales relevantes y fauna), por sí mismas, establecen un criterio de valoración positivo para el resultado que se pretende conseguir. Tanto las zonas de interés faunístico, como las comunidades vegetales más importantes, tienen un valor ecológico en

25 Los intervalos de alturas fueron, para Mallorca, $1=0-200 \mathrm{~m}, 2=200-500 \mathrm{~m}, 3=+$ de $500 \mathrm{~m}$. Para Menorca y Pitiusas los intervalos se redujeron a dos, con la cota de $120 \mathrm{~m}$ y $160 \mathrm{~m}$ respectivamente como límite entre sendas clases.

26 Los intervalos de pendientes fueron, para Mallorca, $1=0-12 \%, 2=12-20 \%, 3=+$ de 500. Para Menorca y Pitiusas los intervalos se redujeron a dos, con el $20 \%$ de pendiente como límite entre ambas clases.

271 = regadío, $2=$ secano, $3=$ pinar, $4=$ encinar, $5=$ matorrales, $6=$ olivar, $7=$ zonas urbanas, $8=$ cuerpos de agua y $9=$ zonas improductivas de costa (playas, acantilados...).

281 = costa y 2 = interior.

29 Con el fin de proporcionar una salida gráfica clara y de fácil comprensión, se han establecido cinco clases finales resultantes con los siguientes intervalos: Paisaje Urbano 0-6, calidad Baja 7-12, calidad Buena 1318, calidad Muy Buena 19-27 y calidad Excelente $>27$. 
sí mismas muy elevado, un interés ecológico máximo. Tan sólo para el caso de las comunidades vegetales se han establecido valoraciones diferentes en el conjunto de sus elementos.

Se han valorado con puntuaciones más altas las comunidades vegetales más frágiles (y por tanto con mayor interés ecológico) como son la vegetación de zonas húmedas, la vegetación dunar o la vegetación de saladar. Con puntuaciones menores se han valorado las comunidades vegetales de bosques de encinares, acebuchales o las comunidades matorrales de romeros y brezos. Y por último se han valorado con un menor peso (lo que no significa sin interés ecológico), los pinares con matorrales esclerófilos y la vegetación sabanoide de carrizo.

De esta forma se han establecido tres gradaciones en función del interés ecológico de las comunidades vegetales. Tres gradaciones o tres valoraciones que en ningún caso deben interpretarse como gradaciones de máximo a nulo interés. El interés científico nulo no puede asimilarse a ninguna comunidad vegetal.

La valoración conjunta del territorio se establece a partir del cruzamiento de las tres componentes básicas mencionadas, una vez valorados los distintos elementos de cada una de ellas. El resultado final es un mapa en el que se definen tres grados de interés ecológico: máximo - yuxtaposición de como mínimo dos elementos con valoración alta—, muy alto - yuxtaposición de uno o dos elementos con valoración alta - y alto — resto de zonas cubiertas por vegetación natural-.

\section{El interés agrológico}

Para la integración en el SIG de este tipo de información se ha utilizado la cartográfica publicada $^{30}$. Partiendo del análisis de las características de les suelos de Baleares, el Mapa de Clases Agrológicas establece ocho grandes clases que hemos sintetizado en cuatro, resultando de esta forma un mapa de interés agrológico de cuatro elementos en función de su aptitud para la explotación agrícola.

Suelos aptos para la agricultura intensiva: incluyen las clases I y II del Mapa de Clases Agrológicas. Son suelos aptos para aplicar sistemas de explotación intensivos, de regadío cuando los recursos hídricos de la zona así lo permitan.

Suelos aptos para el laboreo extensivo: incluye la clase III del Mapa de Clases Agrológicas. Son suelos en los que se pueden aplicar sistemas de explotación extensiva permanente o cualquier otro sistema de intensidad menor.

Suelos aptos para el laboreo ocasional: Incluye la clase IV del Mapa de Clases Agrológicas. Lo constituyen suelos que admiten sistemas de explotación que van desde el laboreo ocasional a la producción forestal.

Suelos no aptos para el laboreo o improductivos: son suelos no apropiados para la explotación agrícola pero pueden ser explotados bajo sistemas de pastoreo, producción forestal o reserva natural.

\section{El mapa de unidades territoriales para la ordenación del medio físico}

De la superposición y análisis conjunto de los tres mapas anteriores (interés paisajístico, ecológico y agrológico) se deducen las grandes opciones de uso del medio físico de la comunidad autónoma. Con la superposición inicial resultaron unos 60.000 polígonos diferentes que se agruparon por categorías y posteriormente fueron disueltos.

30 Mapa de Clases Agrológicas a escala 1:50.000 del año 1988, elaborado por la Dirección General de la Producción Agraria del Ministerio de Agricultura Pesca y Alimentación. 


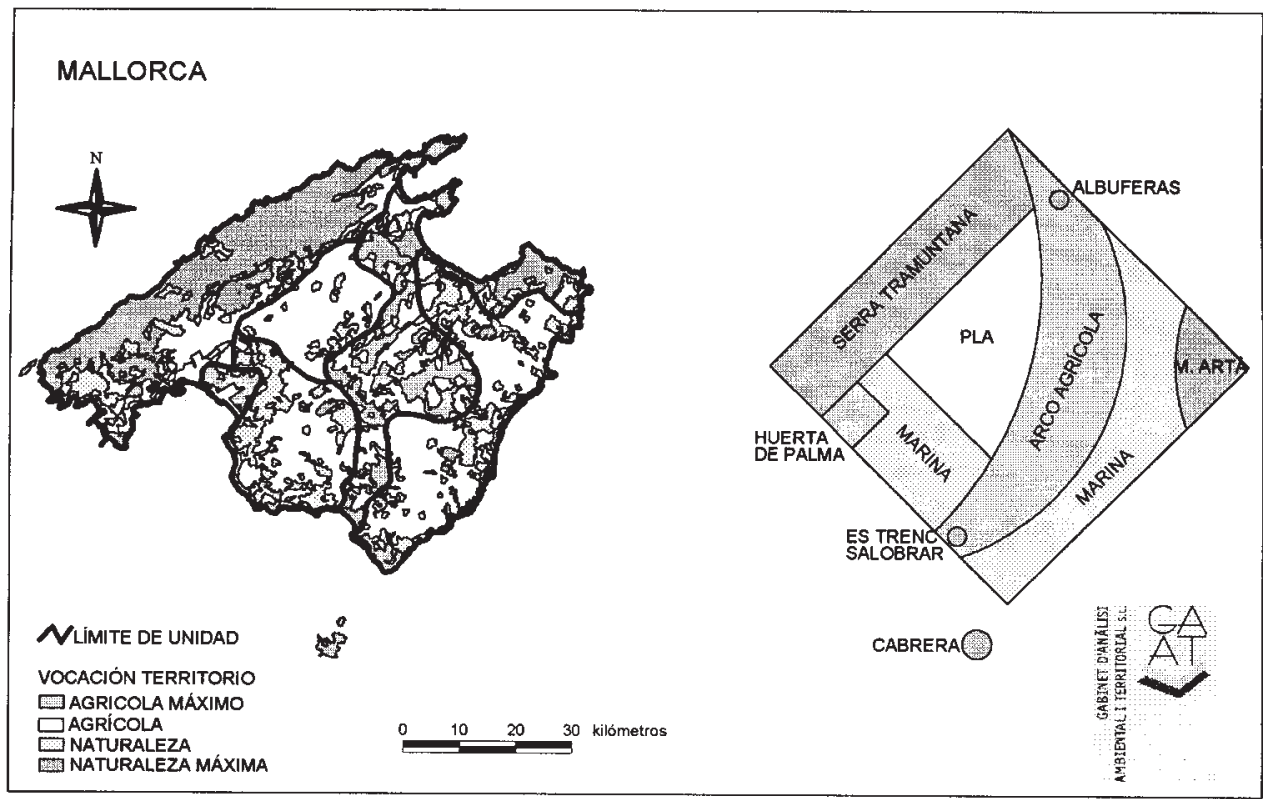

MAPA 3. Unidades territoriales.

\section{MENORCA}
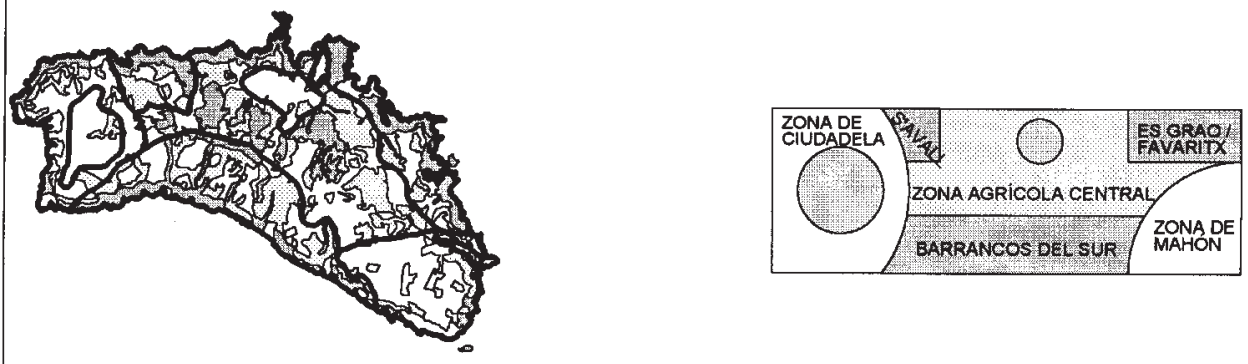

NLIMITE DE UNIDAD VOCACIÓN TERRITORIO Q AGRICOLA MÁXIMO $\square$ AGRICOLA NATURALEZA WATURALEZA MÁXIMA
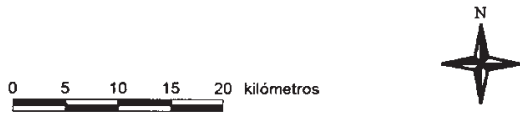

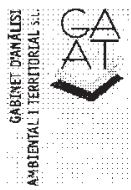

MAPA 4. Unidades territoriales. 
NLIMITE de UnIDAD VOCACIÓN TERRITORIO OWGRICOLA MÁXIMO $\square$ AGRICOLA DNATURALEZA MATURALEZA MÁXIMA
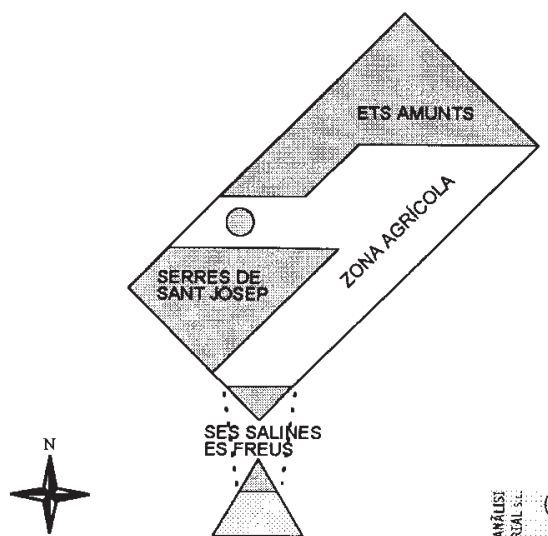
ESFREUS

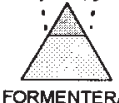

FORMENTERA

MAPA 5. Unidades territoriales.

Se tratará, recordémoslo, de una zonificación de piezas territoriales para las que se sugieren tratamientos comunes entendidos como grandes opciones, con independencia de que en el interior de cada una, como de hecho ocurre, la heterogeneidad de escala más detallada presente vocaciones o intereses distintos.

La diversidad interinsular junto a las diferentes extensiones de las cuatro grandes islas, imposibilitan la comparación de las zonificaciones resultantes. Así, en el interior de Mallorca, hay zonas tan extensas y homogéneas como la totalidad de cada una de las islas menores. Compárese los $1.000 \mathrm{~km}^{2}$ de la serra de Tramuntana con los 716 de Menorca, la mayor de las islas menores.

En un análisis conjunto del archipiélago sólo podríamos elaborar una zonificación del medio físico para el caso de Mallorca, constituyendo cada una de las islas menores unidades territoriales equivalentes a las establecidas en el interior del territorio mallorquín. Hecha esta apreciación debemos advertir inmediatamente que aspectos cuantitativos como $\mathrm{km}^{2}$ carecen de la oportuna consideración cualitativa que debe informar el análisis del medio físico de un archipiélago. Las islas son micromundos en todos los aspectos tanto los derivados del medio físico como los derivados del medio socioeconómico. Con esta premisa hemos zonificado las tres islas mayores, zonificación que no hubiéramos extendido a Menorca e Ibiza de tratar con la misma escala cuantitativa la totalidad del archipiélago balear.

Observando el mapa descrito y haciendo un esfuerzo de abstracción superior, acompañado de apreciaciones cualitativas, las consideraciones cuantitativas planteadas hasta el momento, pueden ser identificadas cuatro tipologías algunas de ellas discontinuas. Esquemáticamente han sido representados mediante lo que se ha venido a llamar coremas ${ }^{31}$. Este

31 La utilización de los coremas se ha popularizado, en España (Cortizo Álvarez 1993), a partir de los trabajos de geógrafos franceses (Brunet 1980). En las Baleares se han empezado a utilizar este tipo de grafismos a partir de la primera mitad de los 90 (Rullán Salamanca 1995b). 
modelo ha sido construido a partir del mapa de vocación del territorio complementado y matizado a partir de consideraciones puntuales (mapas 3, 4 y 5).

MALLORCA. De la observación del mapa de vocación del territorio de Mallorca, y con independencia de los usos urbanos, pueden diferenciarse cuatro grandes vocaciones desde el punto de vista de la potencialidad que ofrece le medio físico: Agricultura Intensiva, Agricultura Extensiva, Protección y Máxima Protección.

Genéricamente la zona de Agricultura Intensiva corresponde a las tres grandes huertas mallorquinas más los terrenos de regadíos y zonas de mayor productividad agrológica de la isla. La zona de agricultura extensiva corresponde a los secanos que se distribuyen por todo el territorio con excepción de la serra de Tramuntana. De entre las zonas de protección se diferencian las de máxima protección (áreas montañosas y litorales) de las que se sitúan en un segundo escalón y que estarían representadas por los encinares y matorrales de interior.

Las unidades de vocación natural se localizan en dos grandes zonas, serra de Tramuntana y montañas de Artà, además de contar con ámbitos superficialmente menores aunque de primerísimo orden en cuanto a la valoración que merecen, es el caso de las albuferas del norte, el Trenc-Salobrar y el subarchipiélago de Cabrera. Estas zonas representarían lo menos desnaturalizado de la isla, donde la conservación debería ser su vocación principal, independientemente de que pudieran aflorar otros usos a otras escalas de análisis y ordenación.

En el otro extremo de la balanza, nos encontraríamos con las zonas más desnaturalizadas, las de vocación agrícola. La agricultura sería la vocación primordial de la unidad localizándose en dos zonas: el Pla de Sant Jordi y lo que hemos llamamos el arco agrícola, una zona esta última que uniría las huertas de sa Pobla-Muro con la de Campos por el área noroccidental del Pla donde, como demuestra el mapa de capacidad agrológica se localizan las mejores tierras de cultivo del interior de la isla.

De la novedad de esta área ya dimos cuenta en otra ocasión ${ }^{32}$. Investigaciones posteriores planteadas desde ópticas ajenas al medio físico la han confirmado al tiempo que han venido a enmarcar como una de las piezas del modelo teórico de utilización del suelo de Robert Sinclair (Binimelis Sebastián 1996, pp. 241-3).

Entre estos extremos se sitúan dos unidades de transición Naturaleza-Agricultura: las Marinas, menos desnaturalizadas, y el interior menos productivo y más desnaturalizado. Las marinas, simbiosis naturaleza-agricultura y zonas de mosaico por excelencia, se localizan en el sur (marina de Llucmajor) y levante (desde el Cap de ses Salines hasta la marineta de Petra). El interior menos productivo es básicamente el llano centro-occidental, donde la vocación agrícola debe de ser obviamente matizada con otros usos complementarios.

MENORCA. Marina unitaria a nivel balear - mosaico entre naturaleza y usos agropecuarios-, diversidad a nivel menorquín. El micromundo de las islas menores merece una zonificación en unidades que no aparecerían desde la generalización de comunidad autónoma.

32 Apuntábamos entonces: La seva naturalesa, com a àrea típicament geogràfica, és doble: física $i$ humana. Els trets físics que el caracteritzen són la qualitat del sòl des del punt de vista agrològic —els millors sòls de Mallorca juntament amb els del Pla de Sant Jordi- i la disponibilitat d'aigua per al reguiu. Una disponibilitat generalitzada als extrems pre-albuferencs de l'arc que cap a l'interior minva fins a esdevenir puntual. (...) Hi ha, a més, un fet humà que reforça l'arc. Aquesta àrea és equidistant del principal focus emissor d'usos incompatibles amb l'agricultura: Palma. La capital irradia la seva influència sobre tota l'illa llançant usos $i$ ocupacions del sòl sobre unes àrees que fins fa poc eren majoritàriament agrícoles. Però, com que els efectes dels fenòmens decreixen amb la distància, el fenomen Palma es fa més poc sensible com més lluny de la capital ens fem. D'aquí que, lògicament, una irradiació com la descrita genera un arc. Quan la feblesa de la irradiació des de Palma és fa més palesa, comença la frontera oest de l'arc agrícola, $i$ si, a més, resulta que aquesta caiguda de la influència metropolitana —un fet humà-coincideix amb la presència dels millors sòls agrícoles de Mallorca —un fet fícic—, l'àrea geogràfica diferenciada està servida. (Rullán Salamanca 1995a, p. 9) 
Las unidades de vocación natural se localizan entre la albufera des Grau, la Mola de Fornells, la Vall y los barrancos de la costa sur. Entre estas áreas nos encontramos con un segundo escalón de vocación natural representado por las elevaciones y encinares interiores. El resto de la isla de vocación agropecuaria fundamentalmente ganadera, presenta tres núcleos de interés. La zona de Ciudadela y norte de Mercadal-Ferreries, donde la ganadería presenta una mayor vitalidad, y el sudoeste de la isla que, junto con áreas marginales del área de Ciudadela, no presenta tanta vitalidad por la competencia con los usos urbanos que en ambas zonas se dan.

IBIZA Y FORMENTERA. Como Menorca, las Pitiusas, desde la óptica balear, representarían una única unidad desde el punto de vista de la caracterización del medio físico. No obstante como en el caso menorquín plantearemos subdivisiones que nos permitan acercarnos a la escala insular.

Los coremas de las Pitiusas plantean una división dicotómica entre las áreas de vocación natural y las más desnaturalizadas. Entre las primeras podríamos diferenciar dos niveles. Por un lado las zonas húmedas del sur de Ibiza y norte de Formentera, es Amunts y las serres de Sant Josep. Por otro el resto de la isla de Formentera. En el otro extremo, las zonas más desnaturalizadas cubrirían el resto de la isla de Ibiza, básicamente la costa suroccidental y el corredor de Sant Antoni, siendo precisamente el pla de Sant Antoni y la zona de Santa Eulària los únicos puntos destacables de interés y vocación específicamente agrícola.

\section{Propuesta de ordenación para las unidades territoriales del medio físico}

En Geografía aplicada las conclusiones se materializan en propuestas de ordenación territorial. Así pues, partiendo de la zonificación de unidades anterior se establecen, como aspecto propositivo del trabajo, los usos propiciados, permitidos y prohibidos de cada una ellas así como las figuras propuestas para la ordenación de detalle y la gestión.

\section{Usos generales de las unidades del medio físico}

Los usos propuestos en sus diferentes posibilidades (propiciados, permitidos y prohibidos), deben de ser entendidos al más alto nivel de generalización. Usos que explican el papel de cada una de las piezas del medio físico, usos globales, usos de escala de ordenación del territorio, usos de escala interinsular y en absoluto exclusivos, al contrario, la diversidad de usos robustece la estructura y lejos de segregar zonificaciones excluyentes debe propiciar la excepción diversificadora. Unas excepciones diversificadoras que deberán aflorar a otras escalas de análisis y de planificación. Situados a escala general el cuadro resumen de usos globales por unidades del medio físico es el representado por la tabla siguiente:

\begin{tabular}{|l|c|c|c|c|c|c|c|c|}
\hline Usos & Co. & Re. & Ga. & Ca. & Si. & Ag. & A.T. & V.F. \\
\hline Natural & 1 & 2 & 3 & 3 & 2 & 2 & 2 & 3 \\
Marinas & 1 & 2 & 1 & 1 & 2 & 2 & 2 & 3 \\
Agricultura Extensiva & 2 & 2 & 1 & 2 & 2 & 1 & 1 & 3 \\
Agricultura Intensiva & 2 & 3 & 1 & 3 & 2 & 1 & $1 / 3$ & 3 \\
\hline
\end{tabular}

Co.: Conservación, Re.: Recreación, Ga.: Ganadería, Ca.: Caza, Si.: Silvicultura, Ag.: Agricultura, A.T.: Agroturismo/Turismo Rural, V.F.: Vivienda familiar.

1: Propiciado, 2: Permitido, 3: Prohibido 
Las cuatro grandes vocaciones aquí establecidas, deben ser tenidas en cuenta, en el caso de las islas menores, como conformantes de una zonificación global que sería equiparable a las marinas de Mallorca. Menorca, Ibiza y Formentera requerirán una pormenorización de usos posterior por parte de los planes de desarrollo que contemple tal singularidad.

Las unidades naturales tendrían como uso propiciado de conservación de sus valores ecológicos y paisajísticos que las singularizan. La permisión de los usos recreativos, silvicultura, agricultura y agroturismo/turismo rural, complementados con los usos residenciales de los núcleos urbanos servirían para propiciar la necesaria actividad económica de estas áreas.

Las marinas, entendiendo estas áreas como simbiosis de naturaleza y agricultura en épocas en que esta no tenía los requerimientos productivistas de la actualidad, los usos propiciados serían los de conservación y los de ganadería y caza, al representar estas últimas las actividades más rentable entre las posibles en estos ámbitos. Como usos simplemente permitidos estarían la recreación, la agricultura, la silvicultura y el agroturismo-turismo rural. Las marinas, como representación en forma de mosaico de la influencia del mar en la primera banda de tierras interiores, deben de seguir jugando este papel de influencia de la costa, siendo ahora el trasfondo agrícola-natural de las grandes líneas costeras de turistización y urbanización.

Las áreas interiores, mucho menos influidas por el mar, presentan una clara vocación para la agricultura y la ganadería que puede y debe ser complementada por la propiciación del agroturismo o bien del turismo rural. A nivel de simple permisión se sitúan el resto de usos tratados en este epígrafe. La singularidad del interior de Mallorca viene determinada por una renta de situación inmejorable respeto al resto del territorio mallorquín, es desde dónde se está más cerca de todos los puntos de la isla. Esta múltiple posibilidad la confiere un carácter abierto a todos los usos de la matriz aquí tratados.

Las zonas de más alta productividad, real o potencial, desde el punto de vista agropecuario deben de ser objeto de un tratamiento especial que les proteja de competencia con otros usos. Así se propician los usos agrícola y ganaderos, prohibiéndose caza y recreación por ser incompatibles con los dos primeros que se quieren primar y proteger. Silvicultura y recreación se permiten por compatibles con la agricultura y ganadería. Dicha compatibilización debe de ser concretada geográficamente en planes de desarrollo posteriores. El agroturismo y el turismo rural en este caso no son tratados igualmente. El primero es propiciado al ser complementario de la explotación agraria a la que ayudará a mantenerse, mientras que el turismo rural es prohibido por representar una competencia funcional incompatible con la actividad agropecuaria que se pretende proteger de otros usos.

La relativamente reducida extensión de la comunidad autónoma combinada con la generalizada profusión de usos residenciales en suelo no urbanizable, obliga a un tratamiento conjunto, para todas las áreas vocacionales, en cuanto al uso de vivienda familiar.

El parque actual de edificación en suelo no urbanizable de las islas Baleares ha sido evaluado en unas 95.000 unidades $^{33}$. A dicha cifra se llega a partir del recuento que para 1987 se hizo para la isla de Mallorca y que evaluó en 53.000 unidades la magnitud del fenómeno (Artigues et al. 1992). El informe temático de planeamiento, en el apartado relativo al SNU evalúa la velocidad real del proceso de implantación de viviendas familiares en SNU en una horquilla que se situaría entre 2.000 y 2.500 unidades residenciales por

33 El análisis específico de la vivienda familiar es, evidentemente, inferior. En un trabajo posterior en el que se analiza esta cuestión, se ha calculado que aproximadamente el 63\% de este parque sería residencial, (Rullán et altes, en prensa). 
año y para la isla de Mallorca. Con lo cual en la actualidad nos situaríamos, en Mallorca, en una cifra próxima a las 70.000 unidades.

Estas unidades estarán situadas en el SNU de régimen general que para Mallorca cubre unos $2.008 \mathrm{~km}^{2}$, cifra esta a la que se llega después de restarle a los $3.641 \mathrm{~km}^{2}$ de la isla los $1.381 \mathrm{~km}^{2}$ urbanísticamente protegidos por la $\mathrm{LEN}^{34}$, y los $252 \mathrm{~km}^{2}$ clasificados de urbano o urbanizable por los planeamientos municipales según el informe temático de planeamiento.

Estas magnitudes suponen una densidad de 34 unidades $/ \mathrm{km}^{2}$, o lo que es lo mismo, una asignación teórica de $30.000 \mathrm{~m}^{2}$ de SNU de régimen general a cada unidad residencial. Para las islas menores no se dispone de las cifras equivalentes pero es de suponer que puede extrapolarse la densidad calculada para Mallorca a la totalidad del archipiélago, pues la mayor densidad de las Pitiusas será compensada la menor densidad de Menorca.

Así el SNU de régimen general de las islas menores asciende a $710 \mathrm{~km}^{2}$, lo que supondría la existencia de unas 25.000 unidades en este tipo de suelo. 70.000 de Mallorca más 25.000 de las islas menores dan un total de 95.000 unidades edificatorias en SNU. La magnitud y velocidad del fenómeno le confiere una dimensión alarmante por lo que se propone la prohibición, con carácter general de la vivienda familiar en SNU. Una medida que ya cuenta con precedentes en otras comunidades autónomas como es el caso de los establecido por las DOT del País Vasco o algunos de los planes insulares canarios.

Esta determinación «en negativo» debe ir acompañada de otras «en positivo» entre las que cabe destacar dos. En primer lugar se trataría de desatascar una importante cantidad de suelo ordenado y no edificado derivado de procesos de urbanización inacabados. En esta línea la Comunidad Valenciana ha empezado a legislar ${ }^{35}$ en avanzadilla de lo que, desde el antiguo MOPTMA pretendía ser la tercera reforma de la ley del suelo (Generalitat Valenciana 1995)

En segundo lugar se trataría de implementar políticas de fomento de la concentración parcelaria en las áreas en que los procesos descritos adquieren mayor velocidad. Para ello resulta imprescindible la intervención pública que debería combinar la compra de SNU con las expropiaciones que le posibilita el artículo 256 de la actual Ley del Suelo. La asunción de situaciones fácticas implica dos importantes inconvenientes que la desaconsejan: deslegitima la disciplina urbanística que debe regir todos estos procesos a la vez que aumentan las posibilidades edificatorias en estos ámbitos.

\section{Figuras de ordenación y gestión propuestas}

Las figuras que ordenación y gestión que se proponen derivan todas ellas de la Ley 4/1989 de Conservación de los Espacios Naturales y la Flora y fauna Silvestre. Las figuras derivadas de la ley del suelo — fundamentalmente planes especiales - y de la LOT - planes directores sectoriales y territoriales parciales - se consideran más propicias para regular usos y actividades no relacionados con el medio físico sino con las actividades socioeconómicas. En cuanto a los planes de ordenación del medio natural, previstos en la LOT balear, se consideran menor adecuados que los derivados, por su mayor diversidad, de la Ley 4/1989.

34 Ley 1/1991, de 30 de enero, de Espacios Naturales y de Régimen Urbanístico de las Áreas de Especial Protección de las Islas Baleares.

35 Ley 6/1994, de 15 de noviembre de la Generalidad Valenciana, reguladora de la actividad urbanística. Publicada en el Diario Oficial de Generalitat Valenciana el 24-11-94, entraría en vigor a los 20 días de su publicación (14-12-94). 


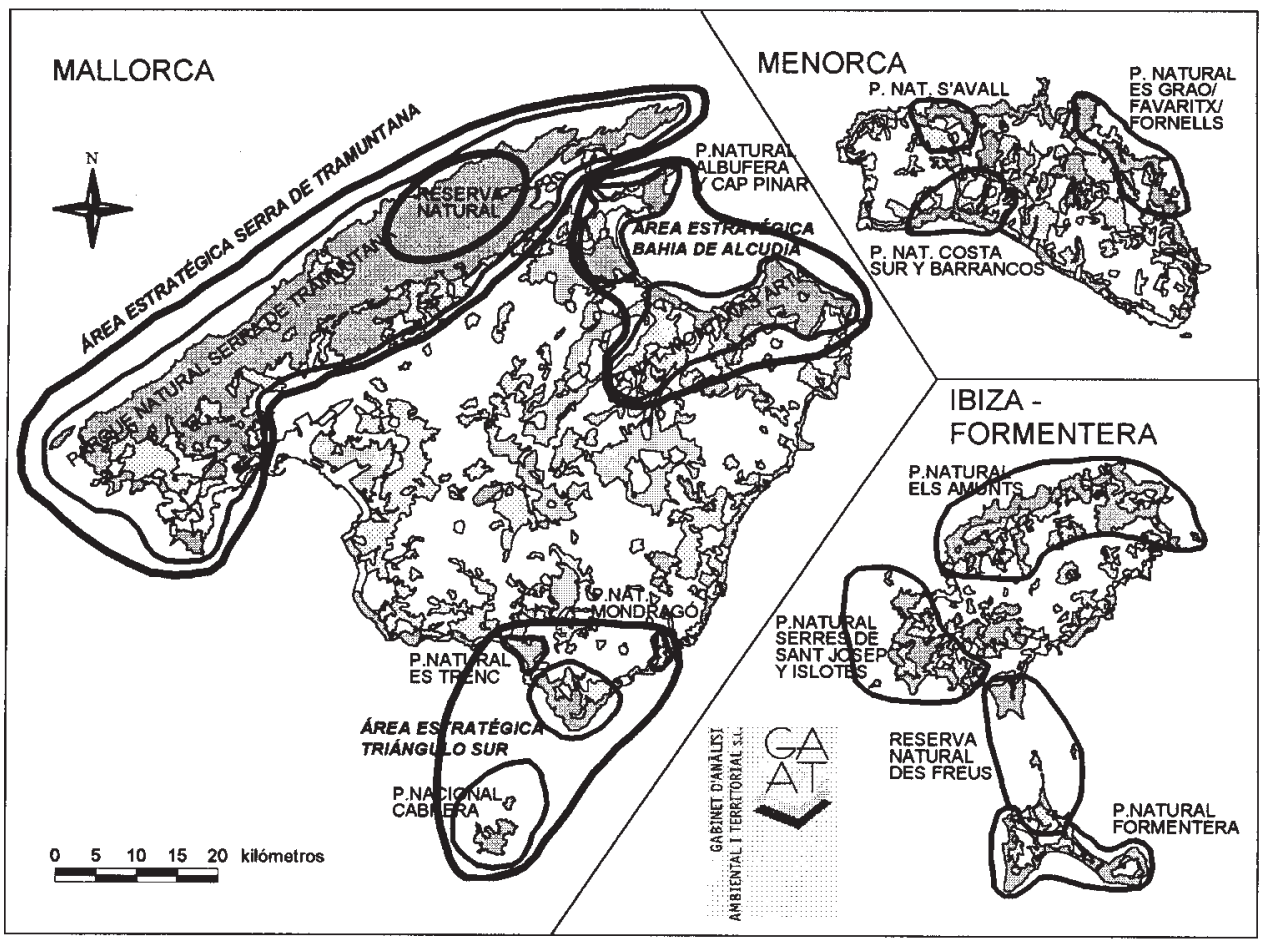

MAPA 6. Propuesta de figuras de ordenación y gestión.

La delimitación de los ámbitos que se reseñan (mapa 6) son puramente indicativos y sometidos a ulteriores análisis de detalle.

Para la isla de Mallorca se proponen tres áreas estratégicas de conservación cada una de las cuales debería ser objeto del correspondiente Plan de Ordenación de Recursos Naturales (PORN): serra de Tramuntana, Bahía de Alcúdia y triángulo sur.

Para toda la serra de Tramuntana se propone indicativamente su declaración como parque natural —incluido el ya declarado de sa Dragonera — y desestimar la ordenación de sus aspectos naturales con un PTP de la LOT según propone la Ley 1/1991 de Espacios Naturales (LEN). Entre Lluc y Pollença, coincidiendo con el área del sapillo partero balear (Alytes muletensis) «ferreret» y el área de máxima densidad de buitre negro (Aegypius monachus), se propone la delimitación de una Reserva Natural según la Ley 4/89.

El área estratégica de la bahía de Alcúdia posteriormente a la elaboración del correspondiente PORN podría comprender dos Parques Naturales diferentes. El primero sería constituido por la ampliación del de la Albufera hasta la Albufereta de Pollença y al Cap des Pinar de Alcúdia, con los núcleos turísticos de Alcúdia (declarado municipio ecológico) como principales beneficiarios de tal declaración. El segundo lo constituirían las montañas de Artà, la marineta de Petra y las zonas dunares de sa Canova y Son Real. Las áreas turísticas de Sant Llorenç, Son Servera y Capdepera serían las zonas que más se beneficiaran de este parque natural.

El área estratégica del triángulo sur podría constituirse por los ya declarados parques nacional de Cabrera, Natural de Mondragó, el natural, previsto por la LEN, del TrencSalobrar y un tercer Parque Natural del cap de ses Salinas que completarían el área. El 
municipio de ses Salines (declarado municipio ecológico) y las zonas turísticas del sur serían los beneficiarios principales de tal área estratégica.

En concordancia con la declaración como reserva de la biosfera y a partir de las vocaciones establecidas, se propone, para Menorca, la redacción del PORN con tres posibles parques naturales para la isla. La extensión del previsto por la LEN en la Albufera des Grau por la costa norte hasta la Mola de Fornells. La declaración del de la Vall, también en la costa norte. Y el de la costa sur de Ciudadela más los barrancos comprendidos entre Binigaus y Cala Mitjana, zonas éstas propuestas por la reserva de la biosfera como zonas núcleo futuras.

El PORN de las Pitiusas debería contemplar las siguientes posibilidades. Unir las Pitiusas mediante la declaración de Reserva Natural del sector des Freus comprendiendo las diferentes salinas del sur de Ibiza y los «estanys» del norte de Formentera. En Ibiza se propone la reconversión del PTP previsto por la LEN en es Amunts en Parque Natural y la declaración como Parque Natural de parte de las serres de Sant Josep delimitado por el oeste por la carretera Vila-Sant Josep-Sant Antoni. Este parque recoge, ampliándola, la previsión de la LEN respeto a los islotes del Vedrà y sa Conillera. Toda la isla de Formentera, no declarada Reserva Natural, se propone declararla como parque natural. Articulando, de esta manera, una oferta turística genuinamente ecológica para la menor de las Baleares.

\section{Referencias bibliográficas}

ALEGRE, P. (1983): Una aplicació del programa MAP a Catalunya, Barcelona, Departament de Geografia de la UAB-Direcció General de Política Territorial de la Generalitat de Catalunya, 160 pp.

ARTIGUES, A.; BINIMELIS, J., RUIZ, M. y RULLÁN, O. (1992): «Los SIG y el suelo no urbanizable. Análisis del poblamiento disperso en Mallorca», Actas del V Coloquio de Geografía Cuantitativa, Zaragoza, pp. 9-45.

BINIMELIS SEBASTIÁN, J. (1996): El procés de rururbanització a Mallorca, [Tesis Doctoral inédita], Departament de Ciències de la Terra-Universitat de les Illes Balears, 3 volúmenes.

BRUNET, R. (1980): «La composition des modèles dans l'analyse spatiale», L'Espace Géographique (París), v. IX/4, 253-265.

CORTIZO ÁLVAREZ, T. (1993): «El Mapa-Modelo de los coremas. El modelo asturiano», Alisios. Revista de Geografía, Tenerife, 103-107.

EGEOGRAN (1983): «Bases para una ordenación territorial de la vertiente sur de Sierra Nevada», Cuadernos Geográficos, Granada, 83-125.

EQUIP TRAMUNTANA (1988): Pla Territorial Parcial de la Serra de Tramuntana. Fase d'Informació i Diagnòstic. Conselleria d'Obres Públiques i Ordenació del Territori-Universitat de les Illes Balears (COPOT-UIB), Palma, 6 volúmenes de texto +1 volumen de mapas + Apéndice + Carpeta de mapas.

GABINET D'ANÀLISI AMBIETAL I TERRITORIAL, (GaaT) (1995): El medio físico de las Islas Baleares. Conselleria d'Obres Públiques i Ordenació del Territori-Govern Balear.

GENERALITAT DE CATALUNYA, (1995): Pla territorial General de Catalunya. Departament de Política Territorial i Obres Públiques de la Generalitat de Catalunya, Barcelona, 660 pp. + 22 mapas.

GENERALITAT VALENCIANA, C.O.P.U.T., (1995): Apuntes sobre la ley reguladora de la actividad urbanística. Conselleria d'Obres Públiques, Urbanisme i Transport-Generalitat Valenciana, València, $120 \mathrm{pp}$.

GOBIERNO VASCO (1994): Directrices de Ordenación Territorial de la comunidad Autónoma del País Vasco. Servicio Central de Publicaciones del Gobierno Vasco, Vitoria, 298 pp.

GÓMEZ OREA, D. (1978): El medio físico y la planificación. Madrid, CIFCA, 299 pp.

GÓMEZ OREA, D.; RUIZ DEL PORTAL MATEOS, A. y BANET Y LÓPEZ DE REGO, L. 
(1978): «Condicionantes del medio físico a la localización espacial de las actividades de planeamiento en la provincia de Vizcaya», Estudios Territoriales, Madrid, 61-81.

GONZÁLEZ BERNÁLDEZ, F. (1973): Estudio ecológico de la sub-región de Madrid. Madrid, COPLACO.

MACHARD, I.L. (1969): Design with Mature. Ney York, Natural History-Press.

MOPU-CEOTMA, (1984): Guía para la elaboración de estudios del medio físico. Madrid, MOPUCEOTMA, 572 pp.

RAMOS, A. (1979): Planificación física y ecológica. Modelos y método, Madrid, EMESA, p. 216.

RUIZ PÉREZ, M.; RULLÁN SALAMANCA, O. y RODRÍGUEZ-PEREA, A. (1991): «Modelo Digital de Análisis Territorial (SEPOT)», Estudios Territoriales (Madrid), 81-105.

RULLÁN SALAMANCA, O. (1995a): «Descoberta de l'arc agrícola», Fora Vila Verd, Palma, p. 7.

RULLÁN SALAMANCA, O. (1995b): «Legislación balear versus territorio y medio ambiente», en Turismo y territorio, Palma, COAB, 153-178.

RULLÁN SALAMANCA, O. (1995c): «Técnicas instrumentales y planeamiento para los años noventa», en Las ciudades españolas a finales del siglo XX, Cuenca, Asociación de Geógrafos Españoles (AGE), 179-198.

RULLÁN SALAMANCA, O.; MANCHADO ROSAS, J. y MARCÚS BELTRÁN, A. (en prensa): «La captación del gradiente residencial en suelo rústico. Una propuesta metodológica ensayada en las islas Baleares», Ciudad y Territorio. Estudios territoriales, Madrid, 28 folios.

TALLER DE IDEAS (1996): Hipòtesis de model territorial, Palma, Govern Balear-COPOT-DGOTMA, 98 pp. 